\title{
Systematic notes on Anopheles Meigen (Diptera: Culicidae) species in the state of Amapá, Brazil
}

\author{
Eduardo S Bergo, Raimundo Nonato P Souto ${ }^{*}$, Allan Kardec R Galardo**, \\ Sandra S Nagaki ${ }^{* * *}$, Daniéla C Calado ${ }^{* * *}$, Maria Anice M Sallum ${ }^{* * * /+}$
}

\begin{abstract}
Superintendência de Controle de Endemias, Secretaria de Estado da Saúde de São Paulo, Araraquara, SP, Brasil *Universidade Federal do Amapá, Macapá, AP, Brasil ** Instituto de Pesquisas Científicas e Tecnológicas do Estado do Amapá, Macapá, AP, Brasil **** Departamento de Epidemiologia, Faculdade de Saúde Pública, Universidade de São Paulo, Av. Dr. Arnaldo 715,
\end{abstract} 01246-904 São Paulo, SP, Brasil

Identification of Anopheles nuneztovari Gabaldón and An. goeldii Rozeboom and Gabaldón based on the male genitalia traits is discussed. An. goeldii is in the synonymy of An. nuneztovari, however, characters of the aedeagus of male genitalia distinguish both species. We hypothesize that An. goeldii may be a valid species, however, further studies using molecular characters, especially ITS2 rDNA sequences will be necessary to elucidate the taxonomic status of the species. An. konderi Galvão and Damasceno and An. forattinii Wilkerson and Sallum are registered for the first time in the state of Amapá.

Key words: Anophelinae - Nyssorhynchus - distribution record - malaria vectors

Control of human malaria transmission was the object of a worldwide campaign in the second half of the XX century. At that time, using DDT, malaria transmission was eliminated from developed countries and from developed areas of developing countries. However, in areas where living conditions were poor, malaria transmission continued to be intense. This is the case in the Brazilian Amazon, where climate and ecological conditions are ideal for the proliferation of malaria vector mosquitoes (Tauil 2006). The Brazilian National Program for Malaria Prevention and Control is divided into nine components (Coura et al. 2006). One of the components is the selective control of vectors. Thus, any measures adopted should be dependent on which mosquitoes species are involved in the dynamics of malaria transmission in a given locality. Consequently, entomological studies are necessary for both knowing the species composition in a certain location and for understanding ecological and biological aspects of those species that have vector potential.

In field collections conducted in Amapá, as part of the studies on the systematics of Anopheles (Nyssorhynchus), we detected the occurrence of several Anophelinae species in rural and suburban areas of the municipality of Macapá, some of which have not been reported in the published literature. Field collections of immature stages and

Financial support: Fapesp (grant 05/53973-0), Unicef/UNDP/ World Bank/WHO Special Programme for Research and Training in Tropical Diseases (grant A50252), CNPq (grant 472485/ 2006-7)

${ }^{+}$Corresponding author: masallum@usp.br

Received 16 February 2007

Accepted 24 April 2007 of adult specimens were carried out between 20 and 30 July, 2006. Vouchers of each species are deposited in Faculdade de Saúde Pública of the Universidade de São Paulo, Brazil.

Collections were carried out in locations with diverse physiognomic characteristics, found in the geomorphologic unit denominated "tabuleiro costeiro" (Instituto de Pesquisas Científicas e Tecnológicas do Amapá 2004). Accordingly, collections were carried out in distinct habitats in areas that ranged from dry land forest environments to alluvial forests with some tidal influence from the Amazon river and its tributaries. Some samples were also obtained from the grasslands with medium-sized gallery vegetation and from perennially flooded fields.

When examining characters of male genitalia of some specimens preliminary identified as An. nuneztovari Gabaldón, it became evident that they were similar to the illustration number 3 in Plate III by Rozeboom and Gabaldón (1941), which illustrates the aedeagus of $A n$. goeldii Rozeboom and Gabaldón. Interestingly, illustrations number 3 and number 5 in Plate III of Rozeboom and Gabaldón (1941) show the aedeagus of An. goeldii, however, it is evident that the illustrations refer to two distinct species. By examining the male genitalia of the holotype of An. goeldii (Fig. 1A, B), it was observed that illustration number 5 is probably of An. goeldii, while number 3 is of other species that was misidentified as An. goeldii.

An. nuneztovari was described by Gabaldón (1940) from male specimens collected in San Carlos, Cojedes, Venezuela. Subsequently, Rozeboom and Gabaldón (1941) described An. goeldii using specimens collected in Boa Vista, Belterra (former Fordlandia), Rio Tapajós, in the state of Pará, Brazil. Lane (1953) transferred An. goeldii to the synonymy of An. nuneztovari. Later, Kitzmiller et al. (1973) examined the polytene chromosomes of three populations of An. nuneztovari from Brazil, two from Western Venezuela and one from Northern Colombia and raised the hypothesis of the existence 

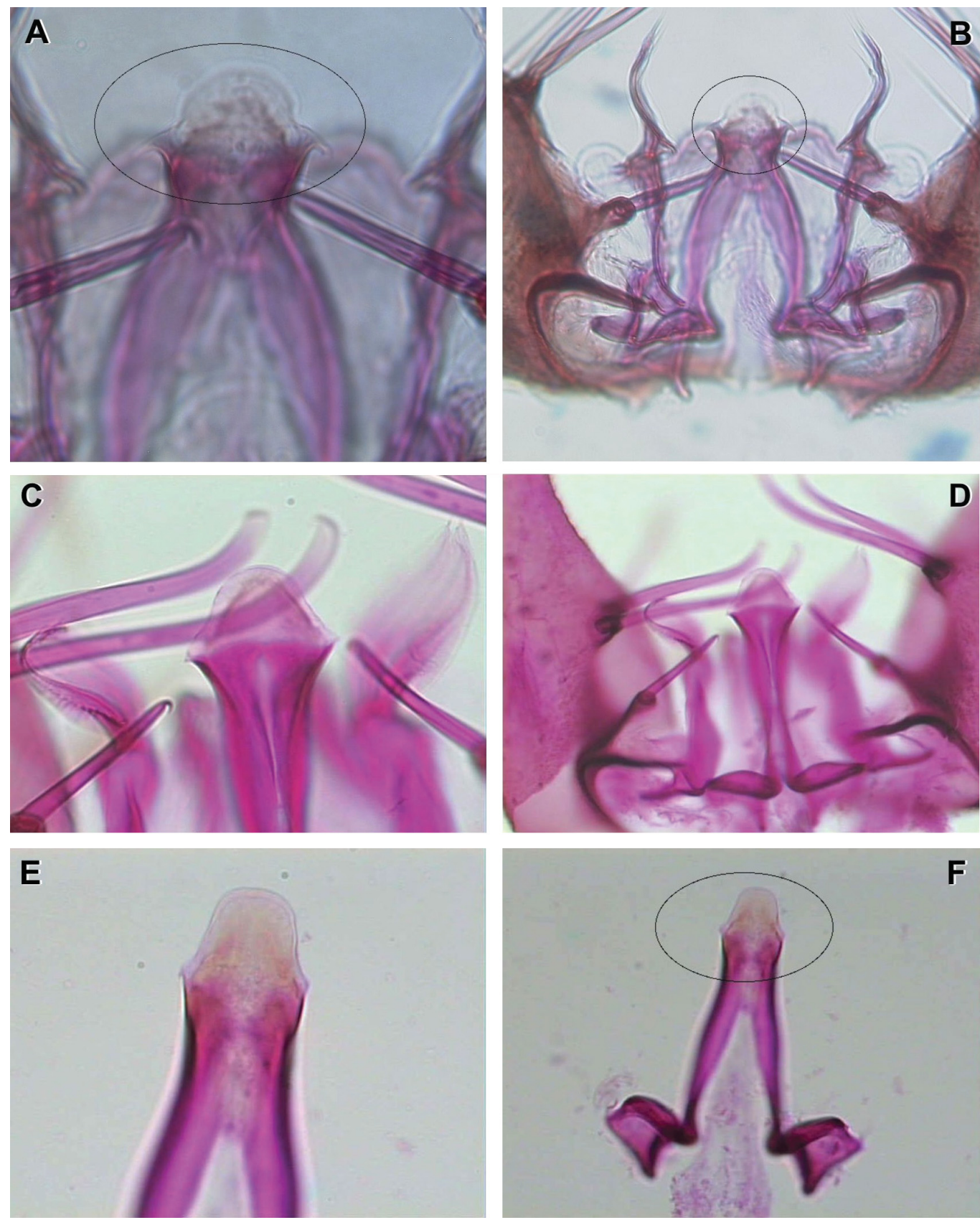

Fig. 1: microphoto of male genitalia, showing details of aedeagus. A, B: Anopheles goeldii, Holotype, collected in Belterra, Rio Tapajós, Pará, Brazil, deposited in the National Museum of Natural History, US; C, D: An. nuneztovari, collected in Parintins, Amazonas, Brazil; E, F: An. near nuneztovari (Amapá form), collected in Macapá, Amapá.

of two species. The Brazilian populations showed a fixed homozygous inversion on the $\mathrm{X}$ chromosome that did not occur in the specimens from Venezuela and Colombia. Continuing Kitzmiller's studies, Conn (1990) analyzed two populations from Venezuela, which were identified as a single panmictic population possessing the chromosome form B. Following this, Conn et al. (1993) designated chromosome form $\mathrm{C}$, which is present in Colombia in areas located to the north and west of the Andes Mountains. In Venezuela, cytotype B occurs in low areas to the west and in the grasslands, between the
Andean Mountains and the Orinoco River basin, continuing towards eastern Colombia. In a recent work, Sierra et al. (2004) examined the variability of four populations of An. nuneztovari from Colombia using the second internal transcribed spacer (ITS2) of nuclear ribosomal DNA sequences and confirmed that cytotypes B and $\mathrm{C}$ represent conspecific forms of An. nuneztovari. In a broader study, Fritz et al. (1994) employed the ITS2 ribosomal DNA sequences to examine An. nuneztovari populations from Brazil, Bolivia, Venezuela, Colombia and Suriname. By doing this, two genetic entities were 

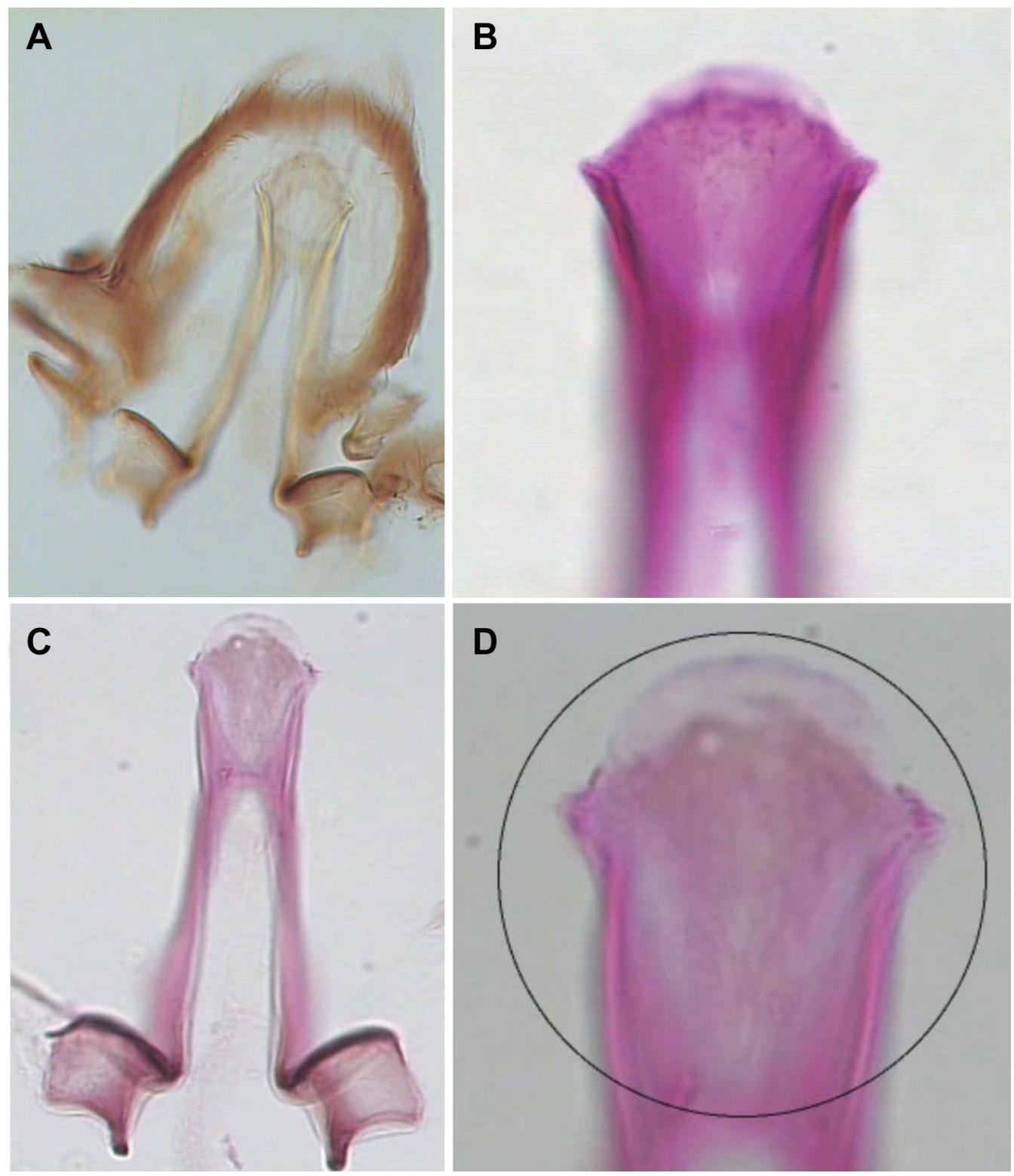

Fig. 2: microphoto of male genitalia, showing details of aedeagus. A: Anopheles konderi, topotype, collected in Coari, Amazonas state; B: An. konderi, collected in Macapá, Amapá; C, D: An. near konderi, collected in Acrelândia, Acre.

found in Brazil, one consisting of Suriname and Northern Brazil populations and a second entity in Eastern and Central Brazil. Similarly, Conn et al. (1998) verified the existence of three genetic forms, one present in Venezuela-Colombia and two on the Amazon river basin by employing mtDNA restriction fragment length polymorphism to analyze 12 populations of An. nuneztovari from Brazil, Bolivia, Colombia, Suriname, and Venezuela. By using the ITS2 sequences, Onyabe and Conn (1999) analyzed the intragenomic heterogeneity of five populations of An. nuneztovari, three from Brazil, one from Colombia and one from Venezuela. As in other studies, the differences observed suggest that An. nuneztovari comprises a complex of two or three species. Concluding, results of distinct source of data suggest that An. nuneztovari comprises a species complex with two sympatric genetic forms (Fritz et al. 1994) in the Brazilian Amazon.

As a result of collections carried out in the Amazonas/ Solimões river basin, including the state of Amapá, samples from various $A n$. nuneztovari populations were obtained. By comparisons of the male genitalia characters, it was possible to infer that those individuals collected in Amapá and identified as An. nuneztovari were distinct from both An. goeldii (Fig. 1A, B) and An. nuneztovari (see Savage, 1986 for details of the holotype). The morphologic form from Amapá occurs in sympatry with An. nuneztovari (Fig. 1C, D) in other localities in Amazon basin. Moreover, all individuals obtained in Amapá possess male genitalia that resembles that illustrated by Rozeboom and Gabaldón (1941) for An. 
goeldii (Plate III, number 3). Male genitalia of specimens from state of Amapá (Fig. 1E, F) and An. goeldii (Fig. 1A, B) can be easily distinguished from that of $A n$. nuneztovari (Fig. 1C, D) by the apex of the aedeagus. Differences in the apex of the aedeagus are largely used to identify species of the subgenus Nyssorhynchus. Consequently, it is possible to infer that the three forms show in Fig. 1 might be of distinct species.

To test the hypotheses that An. goeldii (Fig. 1A, B) is a distinct species from An. nuneztovari and that the morphological form from Amapá might represent an undescribed species more studies, using ITS2 rDNA nucleotide sequences, are being conducted. The ITS2 rDNA sequences generated from adult males collected on the floodplains of the Amazonas/Solimões river basin, including those from Amapá, are going to be compared to others deposited in GenBank from specimens identified as An. nuneztovari cytotypes A, B and C, including those in the alignment published by Fritz et al. (1994). Additionally, as far as possible, topotype specimens of An. goeldii are going to be included in the analyses. The studies are being conducted by Calado et al. (unpublished).

Until recently, An. konderi Galvão and Damasceno was considered to be a synonym of An. oswaldoi (Peryassú). Flores-Mendoza et al. (2004) designated the neotype and conducted a morphologic study of all developmental stages. The ITS2 of several Anopheles (Nyssorhynchus) species sequences that are deposited at GenBank were reanalyzed by Marrelli et al. (2006), using the NeighborJoining algorithm to estimate the distances between them. The results of the analysis showed that the intraspecific variation in An. konderi is 0.3 and the sequences of this species cluster together with others from $A n$. oswaldoi. Comparing the male genitalia of a topotype specimen (Fig. 2A) of An. konderi from Coari, in the state of Amazonas to samples from the state of Amapá (Fig. 2B) and others collected in the state of Acre (Fig. 2C, D), it can be observed that individuals obtained in Amapá resemble An. konderi (topotype) more than the ones obtained in Acre. Obviously, more in-depth studies must be developed to assess whether these morphologic differences represent either distinct species or variation in An. konderi.

Other species that deserve mention is An. forattini. During collections in "São José do Mata Fome" community and "Abacate da Pedreira" community, both rural areas near Macapá, individuals of An. forattinii Wilkerson and Sallum were collected. In Abacate da Pedreira, a single fourth instar was collected in a larval habitat situated at the edge of AP070 Road. Therefore, this is the first time An. forattinii is registered in the state of Amapá. The species identification was done using larval characters in addition to those of the adult female.

\section{ACKNOWLEDGMENTS}

To RC Wilkerson (WRBU, US) for comments and suggestions that greatly improved the manuscript, and Judith Stoffer (WRBU, US) for the microphotos of the male genitalia of the holotype of An. goeldii. To Instituto de Pesquisas Científicas e Tecnológicas do Amapá, to Universidade Federal do Amapá, to Jorge P Duarte and Aderbal A Santana for their valuable help in collecting samples.

\section{REFERENCES}

Conn JE 1990. A genetic study of the malaria vector Anopheles nuneztovari from western Venezuela. J Amer Mosq Control Assoc 6: 400-405.

Conn JE, Mitchell SE, Cockburn AF 1998. Mitochondrial DNA analysis of the neotropical malaria vector Anopheles nuneztovari. Genome 41: 313-327.

Conn JE, Puertas YR, Seawright JA 1993. A new cytotype of Anopheles nuneztovari from western Venezuela and Colombia. J Amer Mosq Control Assoc 9: 294-301.

Coura JR, Suarez-Mutis M, Ladeia-Andrade S 2006. A new challenge for malaria control in Brazil: asymptomatic Plasmodium infection - A review. Mem Inst Oswaldo Cruz 101: 229-237.

Flores-Mendoza C, Peyton EL, Wilkerson RC, Lourenço-deOliveira R 2004. Anopheles (Nyssorhynchus) konderi Galvão and Damasceno: neotype designation and resurrection from synonymy with Anopheles (Nyssohynchus) oswaldoi (Diptera: Culicidae). Proc Entomol Soc Wash 106: 118-132.

Fritz GN, Conn J, Cockburn A, Seawright J 1994. Sequence analysis of the ribosomal DNA internal transcribed spacer 2 from populations of Anopheles nuneztovari (Diptera: Culicidae). Mol Biol Evol 11: 406-416.

Gabaldón A 1940. Estudios sobre anofelinos. Serie I. 1. Descripcion de Anopheles (Nyssorhynchus) nunez-tovari n. sp. y consideraciones sobre una sub-division del grupo Nyssorhynchus (Diptera: Culicidae). Publ Div Malar 5: 3-7.

Instituto de Pesquisas Científicas e Tecnológicas do Amapá 2004. Programa Estadual de Gerenciamento Costeiro. Projeto Zoneamento Ecológico-Econômico do Setor Costeiro Estuarino. Mapa de Dinâmica Geomorfológica, carta 2/3 (www.iepa.ap.gov.br, accessed on 29/01/2007).

Kitzmiller JB, Kreutzer RD, Tallaferro E 1973. Chromosomal differences in populations of Anopheles nuneztovari. WHO Bull 48: 435-455.

Lane J 1953. Neotropical Culicidae, Vol. I, Editora da Universidade de São Paulo, São Paulo, 548 pp.

Marrelli MT, Sallum MAM, Marinoti O 2006. The second internal transcribed spacer of nuclear ribosomal DNA as a tool for Latin American anopheline taxonomy - A critical review. Mem Inst Oswaldo Cruz 101: 817-832.

Onyabe DY, Conn JE 1999. Intragenomic heterogeneity of a ribosomal DNA spacer (ITS2) varies regionally in the neotropical malaria vector Anopheles nuneztovari (Diptera: Culicidae). Insect Mol Biol 8: 435-442.

Rozeboom LE, Gabaldón A 1941. A summary of the "tarsimaculatus" complex of Anopheles (Diptera: Culicidae). Am J Hyg 33: 88-100.

Savage HM. 1986. Identification and location of the holotype and paratypes of Anopheles (Nyssorhynchus) nuneztovari Gabaldón (Diptera: Culicidae). Mosq Syst 18:279-283.

Sierra DM, Velez ID, Linton YM 2004. Malaria vector Anopheles (Nyssorhynchus) nuneztovari comprises one genetic species in Colombia based on homogeneity of nuclear ITS2 rDNA. J Med Entomol 41: 302-307.

Tauil PL 2006. Perspectives of vector borne diseases control in Brazil. Rev Soc Bras Med Trop 39: 275-277. 